\title{
Vascular endothelial growth factor association with angiopoietin 1 promotes improvement in ventricular function after ischemic cardiomyopathy induced in mini pigs ${ }^{1}$
}

André Lacerda de Abreu Oliveira', Jussara Peters Scheffer", Melissa Markoski"l, Andreia Koche ${ }^{\mathrm{IV}}$, Alexsandra Balbinot ${ }^{\mathrm{IV}}$, Fernanda Antunes ${ }^{\mathrm{V}}$, Renato Kalil"II

'PhD, Associate Professor, Laboratory of Animal Health, Center for Agricultural Sciences and Technologies, Animal Experimentation Unit, Universidade Estadual do Norte Fluminense Darcy Ribeiro (UENF), Campos dos Goytacazes-RJ, Brazil. Technical procedures, critical revision, final approval the manuscript.

"Fellow PhD degree, Laboratory of Animal Health, Center for Agricultural Sciences and Technologies, Animal Experimentation Unit, UENF Darcy Ribeiro, Campos dos Goytacazes-RJ, Brazil. Conception and design of the study, technical procedures, acquisition and analysis of data, manuscript preparation.

I'PhD, Associate Professor, Institute of Cardiology of Rio Grande do Sul, University Foundation of Cardiology, Porto Alegre-RS, Brazil. Critical revision, final approval the manuscript.

IVPhD, Associate Professor, Institute of Cardiology of Rio Grande do Sul, University Foundation of Cardiology, Porto Alegre-RS, Brazil. Technical procedures.

VPhD, Associate Professor, Laboratory of Animal Health, Center for Agricultural Sciences and Technologies, Animal Experimentation Unit, UENF Darcy Ribeiro, Campos dos Goytacazes-RJ, Brazil. Technical procedures.

\section{Abstract}

Purpose: To investigate the safety and clinical, hemodynamic and tissue improvement ability in mini pigs undergoing cell and gene therapy for the treatment of acute myocardial infarction. Methods: Thirty-two mini pigs Br1 lineage, 12 months old, undergoing induction of acute myocardial infarction by occlusion of the diagonal branch of the paraconal coronary. They were divided into 4 groups: one control group and 3 treatment groups (cell therapy and gene cell therapy). Echocardiography reviews were performed on three occasions and histopathological analysis was performed after 4 weeks. Analysis of variance (ANOVA), Tukey and Wilcoxon tests, were performed.

Results: Association of vascular endothelial growth factor (VEGF) with angiopoietin1 (Ang1) presented satisfactory results in the improvement of ventricular function following ischemic cardiomyopathy in mini pigs when compared to the results of the other treated groups.

Conclusion: The therapy with VEGF and the combination of VEGF with Ang1, promoted recovered function of the myocardium, characterized by reduced akinetic area and induction of neovascularization.

Key words: Genetic Therapy. Myocardial Infarction. Tissue. Swine, Miniature. 


\section{Introduction}

The progressive rise in the prevalence and incidence of cardiovascular disease is a public health problem of increasing interest. Heart disease is a major cause of death in industrialized countries. Heart failure is characterized by an uncompensated reduction in the number of viable and functional cardiomyocytes ${ }^{1}$. The available therapies improve the prognosis of cardiac patients, but are often palliative. An eventual severe cell death associated with myocardial infarction results in the formation of a fibrotic and non-contractile area which contributes to the development of congestive heart failure condition that is associated with high mortality ${ }^{2,3}$. The self-renewal ability of the adult heart is minimal. Cellular and gene therapies could induce neoangiogenesis promoting myocardial revascularization ${ }^{3}$.

The pharmacological, interventional and surgical treatments of ischemic cardiomyopathy have limitations and are unable to prevent the loss of cardiomyocytes and the formation of fibrosis. Injection of stem cells in regions adjacent to the focus of injury could recruit resident stem cells of tissue by stimulating the synthesis of chemotactic molecules, a process which assists in both the repair of the initial injury ${ }^{4-6}$ and the reduction of collagen deposition and fibrin formation ${ }^{5}$. Mesenchymal stem cells (MSC) are of particular interest in cellular therapy because they have great potential for releasing paracrine factors. Also, have the plasticity of multipotent cells. The MSC have advantages of being easily isolated, especially considering the adipose tissue and bone marrow as a source, they have the capacity of propagating in culture and do not present immunogenicity ${ }^{5,7,8}$.

Gene therapy includes a set of techniques aimed at the insertion and expression of exogenous genetic material into cells and/or bodies for therapeutic purposes. Studies performed in the last ten years have shown that the regeneration of injuries caused by acute and subacute myocardial infarction could be better achieved when used vectors for expression of vascular endothelial growth factor (VEGF), epidermal growth factor (EGF) and Growth Factor fibroblasts (FGF), compared with the treatment of chronic myocardial infarction using these proteins ${ }^{9,10}$.

The objectives of this study are to test the safety and clinical, hemodynamic and tissue improvement ability in mini pigs, undergoing cell and gene therapy for the treatment of acute myocardial infarction. The animals underwent cell therapy with stem cell injection from the isolated stromal fraction of the adipose tissue and gene therapy via injection of plasmids expressing VEGF and VEGF combination with Angiopoietin1 (Ang1).

\section{Methods}

\section{Vectors preparation}

The plasmid vector containing the gene for VEGF165 (PEX-HV5) was developed and tested in humans for our group ${ }^{11}$. The vector for the expression of plasmidial Ang1, was built in the Molecular and Cellular Cardiology Laboratory from the IC/FUC by obtaining the complete human CDNA and cloning in the vector pcDNA TOPO TA (Invitrogen). The vector was named pcDNA-derived Ang1. The large scale production of both vectors was performed using PureLink maxi-prep kit (Invitrogen). DNAs were resuspended in saline solution $(0.9 \% \mathrm{NaCl})$ in a concentration of 1 $\mathrm{mg} / \mathrm{mL}$ for Injections in mini pigs.

\section{Cellular processing}

For isolation of the stromal fraction, 10 to 20 grams of submental adipose tissue was collected. The tissues were digested with $1 \mathrm{mg} / \mathrm{ml}$ collagenase Type I (Sigma-Aldrich) for $40 \mathrm{~min}$ at $37^{\circ} \mathrm{C}$ under agitation. After this period, the enzyme was inactivated in cell 
culture medium containing serum, the cells were washed with saline solution, centrifuged and resuspended in the same solution, in a $10^{8}$ cells $/ \mathrm{ml}$ concentration and immediately injected into the animals.

\section{Experimental model}

The study was approved by the Research Ethics Committee, Institute of Cardiology of Rio Grande do Sul/FUC (number 4332/2009).

Twelve-month-old mini pigs with $\mathrm{Br} 1$ lineage were used $^{12}$, which were produced in Brazil by the company Minipig Resarch and Development. The animals were kept in the Animal Experimentation Unit of the Universidade Estadual do Norte Fluminense Darcy Ribeiro, with supply conditions, lighting and hygiene recommendations by the producers and used as adults weighing between 40 and $50 \mathrm{~kg}$.

\section{Anesthetic protocol}

The animals were pre-anesthetized with acepromazine hydrochloride at a dose of $0.2 \mathrm{mg} / \mathrm{kg}^{-1}$, intramuscularly. Twenty minutes after administration of premedication, catheterization was performed in the ear vein by introducing a catheter gauge 20 (24G) (BD-Insyte-ind Becton Dickson. Ltda ${ }^{\circ}$ surgical -11); antisepsis of the region with alcohol 70 was made in the anesthesia area of induction. The anesthesia was carried out with the combination of propofol/thiopental sodium at a ratio of 1:1, homogenized in a 20 $\mathrm{ml}$ syringe, and administered as a dose-effect. The propofol/thiopental sodium intravenous anesthesia association was maintained from the examination of preoperative echocardiography until the time of surgery.

Each animal was placed in a supine position and was introduced tracheal intubation. For anesthesia, a closed inhalation system was used, coupled to the endotracheal tube. The animals received isoflurane with oxygen. They remained under inhalant anesthesia until the end of the surgical procedure. We used the same protocol described for obtaining submental adipose tissue.

\section{Myocardial infarction model}

A left thoracotomy in the 5th intercostal space approach was made. Acute myocardial infarction was induced by occlusion of the diagonal branch of paraconal coronary (in humans the anterior descending coronary artery) with non-absorbable monofilament 6-0 polypropylene (Prolene - Ethicon ${ }^{\circ}$ ). The successful completion of the infarction was verified by observing the development of a pale color in the corresponding myocardium (Figure 1).

After the procedure, the animals were kept for 4 weeks in an appropriate environment to recover. In the postoperative period the animals continued to receive broad spectrum antibiotics for 7 days and nonsteroidal anti-inflammatory for 5 days, both medications intramuscularly. The surgical wound was cleaned with sterile saline and silver sulfadiazine spray was applied twice a day until healing was complete.

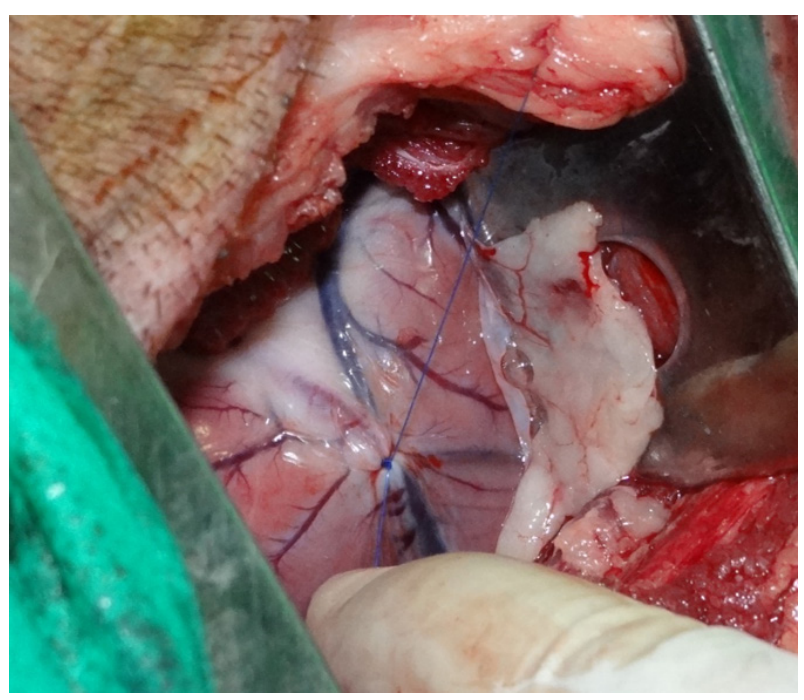

Figure 1 - Mini Pig heart. Display the main diagonal branch of paraconal coronary (in human the anterior descending coronary artery) being occluded by ligature with cardiovascular polypropylene suture 6-0. 


\section{Cell and gene therapy}

Shortly after induction of the infarction, $2 \mathrm{ml}$ of sterile saline solution was applied, containing the corresponding plasmid or stromal fraction of the stem cells at 10 points (about $0.2 \mathrm{ml}$ at each point) around the area of ischemic myocardium according to the treatment group. The application was done with the help of Butterfly 27F needles attached to type of $1 \mathrm{ml}$ insulin syringes.

The animals were divided into 4 groups as follows: Group 1 - control, only the application of sterile saline solution was conducted; Group 2 - treated with VEGF that received VEGF 165 plasmid solution in $2 \mathrm{ml}$ of sterile saline solution; Group 3 - treated with VEGF + Ang1, which received the plasmid VEGF165 + Angiopoietin1 compound in $2 \mathrm{ml}$ of sterile saline solution and Group 4 - treated with stromal fraction of adipose derived stem cells. Each group consisted of 8 animals.

\section{Echocardiographic assessment}

The animals were assessed by transthoracic echocardiography at three different moments. The first and second times were immediately before and after induction of ischemia. The third was immediately before sacrifice procedure thus 4 weeks after surgery. The echocardiographic examination was performed with theanimals anesthetized in a left lateral decubitus position. Echocardiographic measurements followed the recommendations of the M Mode Standardization Committee of the American Society of Echocardiography and the images were taken at a $13.0 \mathrm{MHz}$ frequency. At the level of the papillary muscles from the left ventricle view (cross-section) $M$ mode was carried out and measurements were obtained of the following variables: diastolic and systolic diameter from the left ventricular and akinetic area. The variable of left ventricular ejection fraction was obtained from the modified Simpson method, since it is a more reliable method of infarcted hearts than those obtained only from the $\mathrm{M}$ mode.

\section{Animals sacrifice}

The animals were sacrificed under general anesthesia by intravenous thiopental sodium administration. The sacrifice was performed 4 weeks after the infarct induction.

\section{Histopathological evaluation}

Following sacrifice, the heart was collected, washed and fixed in $10 \%$ neutral buffered formalin solution. Once fixed, four samples were collected as follows, left ventricular fragments injured and not injured, right ventricle fragments injured and not injured. These were arranged in plastic histossette for processing and forwarded to the morphology Sector of the Morphology Laboratory and Animal Pathology/UENF. Samples were stained with hematoxylineosin for evaluation by light microscopy amendments: hydropic degeneration, diffuse inflammation, wound healing, necrosis and neovascularization.

\section{Statistical analysis}

Statistical analysis was achieved using analysis of variance (ANOVA) with repeated measures for the variables of ejection fraction of the left ventricle, diastolic and systolic diameters of the left ventricle to check the effects of the cell therapy/ gene therapy treatment group and the effect of moments of assessment of animals, using the GLM procedure ${ }^{13}$. Turkey test was applied for means comparison. Wilcoxon test was used for analysis of the akinetic area with medians and interquartile ranges. Results were considered significant when $\mathrm{p}$ was less than 0.05 . 
Analysis of neovascularization was carried out using ANOVA of repeated measurements to compare the effects of cell/ gene therapy treatments and the effects of the evaluation time, using the GLM procedure ${ }^{13}$. The means were compared by Tukey test $(p<0.05)$.

\section{Results}

The operations had an average duration of 24.5 minutes. All animals were fully recovered from anesthesia after twelve hours of the surgical procedure, with normal food and water intake.

None of the animals showed clinical signs that featured deleterious effect of ischemic cardiomyopathy, such as apathy, anorexia or respiratory changes in the short or long term in the postoperative daily evaluations. Complications or behavioral changes related to surgical wounds were observed (pain, wound dehiscence, etc.).

\section{Akinetic area}

The akinetic area was evaluated only in the second and third times (immediate postoperative period and 4 weeks after surgery), by transthoracic echocardiography examination. Significant differences were found between the group's means in the assessed moments (Figure 2). Both stromal fraction and the combination of the two vectors (VEGF + Ang1) showed a decrease in the area after 30 days ( $p=0.007$ and $p=0.028$, respectively). The combination of the two vectors was capable of reducing the area over $20 \%$. Other echocardiographic parameters showed no significant results.

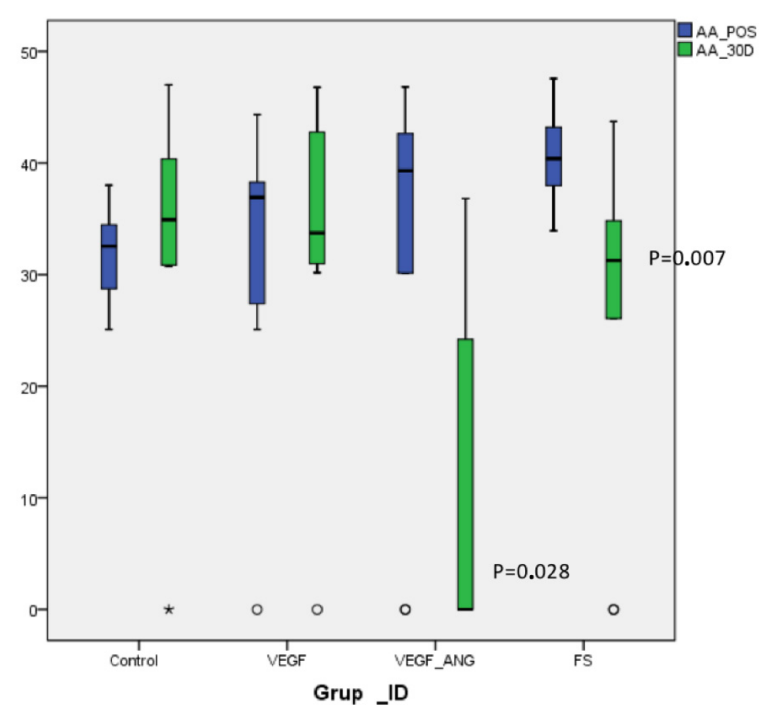

Figure 2 - Mean and standard deviation of the akinetic area figures from each group (Grupo_ID) and estimated time. AA_POS - Immediate post operative time, AA_30D - time after 30 days.

\section{Neovascularization}

The heart tissue samples were processed and analyzed by light microscopy for evaluation of neovascularization.

On amendment of neovascularization group 1 had the lowest average (19.40) and differs from the average of the other groups $(P<0.05)$ and group 2 (average 31.50), however this has a higher average neovascularization in histopathology compared to group 1 . The groups with the highest averages are groups 3 and 4 (49.40 and 42.40 respectively) which do not differ $(P>0.05)$, but differ from groups 1 and $2(P<0.05)$ (Table 1$)$.

Table 1 - Means and their standard deviation (SD) values of neovascularization in accordance with the treatment group.

\begin{tabular}{cc} 
GROUP & MEAN \pm SD \\
\hline 1 & $19.40 \pm 8.43$ \\
2 & $31.40 \pm 8.43$ \\
3 & $49.40 \pm 8.43$ \\
4 & $42.40 \pm 8.43$ \\
\hline
\end{tabular}

Means followed by different letters are significantly different by Tukey test at $5 \%$ probability $(\mathrm{P}<0.05)$. 


\section{Diffuse hydropic degeneration}

For the diffuse hydropic degeneration, it was observed that the groups 1, 3 and 4 had a higher percentage of mild hydropic degeneration (68.3\%, 56.71\% and $71.7 \%$ ). And group 4 presented the best result regarding treatment with an average of $71.7 \%$. Only group 2 had a highest percentage of moderate hydropic degeneration at 45\%. Regarding severe hydropic degeneration, Group 4 had the lowest average with only $1.7 \%$.

\section{Inflammatory process}

In the assessment of this change, it can be observed that all groups showed prevalence of mild inflammation, with values in percent of $70 \%, 86.7 \%, 56.7 \%$ and $76.7 \%$ respectively while group 3 was the one with the highest percentage within the moderate degree of change, with $25 \%$. The group with the highest percentage of absence of this change was the group 1 with $18.3 \%$.

\section{Healing process}

In the healing process, group 1 had no collagen deposition, while groups 2, 3 and 4 presented a small percentage. Group 3 had the highest collagen deposition percentage (38.3\%). Heart collagen deposition in the ischemic tissue area is undesirable because it causes the formation of a scar, which turns the area afunctional, since it reduces muscle contraction capacity. So the higher the percentage of lack of collagen deposition within the groups is better, and we can conclude that all groups showed satisfactory results.

\section{Tissue necrosis}

In relation to tissue necrosis, it was observed that the treated groups (groups 2, 3 and 4) have better results than the control (group 1). Group 1 had the highest percentage of presence of tissue necrosis, which is an undesirable change. Better results were also observed for the groups 2 and 4 when compared to group 3, because the group 3 presented the highest percentage of tissue necrosis (16.7\%), higher than the other two groups (group 2 - 5\% and group $4-3.3 \%$ ) (Figure 3 ).

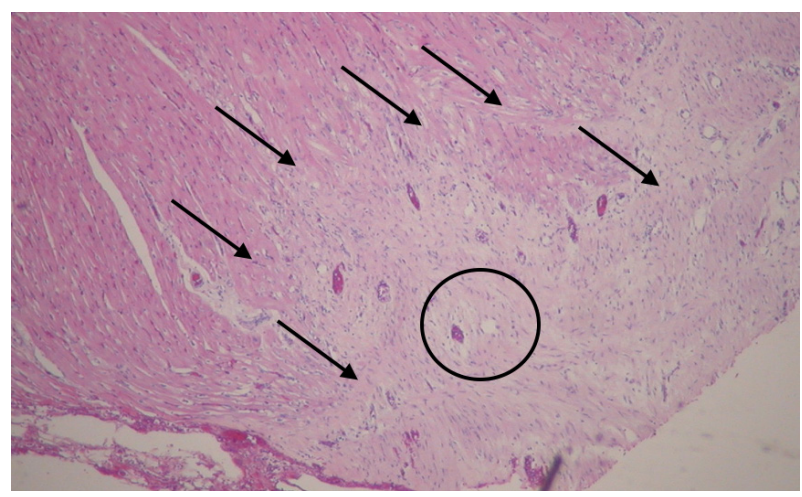

Figure 3 - Histological section heart mini pig. Mild, moderate diffuse hydropic degeneration in the pericardial and endocardial region (arrow). Inflammatory mononuclear moderate diffuse. Light diffuse fatty infiltration. Light diffuse vascular congestion. Necrosis focus in the endocardial region (circle). Hematoxylin-eosin $x 40$.

\section{- Discussion}

The stem cell and gene therapy represent an important therapeutic potential to mitigate injuries caused by ischemic lesions in the myocardium, due to its high incidence, constituting one of the main problems of public health.

Using the mini pig as an experimental model, it was possible to reproduce the acute myocardial infarction after occlusion of the diagonal branch of paraconal coronary (equivalent to the anterior descending coronary artery in humans). Together with the ease of handling, safety and efficacy in the procedures performance, its use is justified by its resemblance to the biochemistry, morphology and cardiovascular physiology with the human species ${ }^{12}$. 
The mesenchymal stem cells derived of the adipose tissue stromal fraction are particularly attractive due to their facility to be obtained in large amounts with a single sample, the high frequency $(0.5 \%)$ and rapid expansion in vitro ${ }^{14}$, so that in the last five years they have received more attention than cells collected from bone marrow. Also, they have plasticity multipotent cells with the ability to differentiate into bone, cartilage, adipose, muscle, epithelia, and more recently, neural tissue ${ }^{8}$, and the ability of self-renewal ${ }^{5,6,15}$, so they are able to multiply, maintaining their undifferentiated state and are present in the perivascular region. Although their differentiation capacity is more limited than embryonic stem cells, they have some advantages, such as easy isolation, ability to spread in culture and that they are not immunogenic ${ }^{5,8}$.

Early administration of cell and gene therapy can be justified due to the interstitial myocardial edema after revascularization, which persists for at least seven days, in addition to the progressive increase of microcirculation obstruction within 48 hours that limits the proper distribution of the therapy ${ }^{11}$. In addition, it has been demonstrated that the injection of a large number of cells early after an ischemic event results in improved fixation index when compared to the use of mesenchymal stem cells in the first and fourteenth days after infarction, suggesting the theory that these cells act specifically in response to ischemia ${ }^{16}$.

The choice of the intramyocardial route was based on literature results. According to Bartunek et $a l{ }^{17}$, the intramyocardial route makes it possible to transplant a sufficient number of cells to the ischemic region. Intravenous infusion does not provide a measurable number of cells and the possibility of microinfarcts formation due to embolism culminates with occlusion of the microcirculation ${ }^{14,17,18}$. According to Angeli and
Oliveira ${ }^{19}$, the intracoronary route should be used only when one is certain of the integrity of the coronary tree, allowing for effective distribution of therapies.

The size of the akinetic area, due to the heart attack, is indicative of the severity of the ischemic event. The more severe ischemia suffered by infarction the larger the akinetic area will be. One of the objectives of the use of cell and gene therapy is to promote the reduction of the area and improve myocardial contractility.

Group 3 also showed better results in relation to variable akinetic area, as it showed a significant decrease of $61 \%$ (increase of $4 \%$ in group 1 , and $3 \%$ in group 2, 34\% decrease in group 4), while the group of VEGF showed an increase of akinetic area of $3 \%$, which is consistent with studies reports ${ }^{20}$, the VEGF association with Ang1 produces a better effect than either factor used in isolation. These results suggest that the combined treatment of VEGF + Ang1 could be used to produce therapeutic vascularization and consequently decreased akinetic area.

The treated groups showed significant difference in neovascularization when compared with the control group, and the groups treated with VEGF and Ang1 + stromal fraction showed better results $(49.40 \%$ and $42.40 \%$ respectively), but did not differ significantly between itself, indicating the angiogenic effect of the treated groups. The hypoxia and ischemia occurring after arterial occlusion are the natural biological stimulus for endogenous angiogenesis. Therapeutic angiogenesis occurs when using VEGF, angiogenic cytokines or cell therapies in order to accelerate and promote the neovascularization process, improving perfusion and cardiac function ${ }^{21}$.

The greatest reduction of akinetic area of VEGF + Ang1 group also presented the highest percentage of neovascularization 
(49.4\%), thereby increasing the vascularization of the injured area, showing a correlation between the events into the morphofunctional myocardial recovery. Chae et al. $^{20}$ reported in his study with peripheral ischemia an increase in blood flow and neovascularization observed in angiographic analysis; the combination of VEGF + Ang1 produced larger blood vessels generation after this therapy.

Nevertheless VEGF + Ang1 group presented discrepant results compared to other studies in this area, as it presented worsening of the amounts related to ejection fraction and diastolic and systolic diameter of the left ventricle. The expected result with the VEGF + Ang1 association is the improvement of organ contractility and consequently increased ejection fraction and decrease in diastolic and systolic diameters, as described by several authors ${ }^{22-24}$. This result raises some questions, such as: Will a long-term evaluation echocardiographic (three months after application) reveal improvement in ejection fraction values?

The group in which only VEGF was used showed significant difference $(P<0.05)$ as compared to VEGF + Ang1 group (mean $31.4 \%$ and $49.4 \%$ respectively), which confirms the hypothesis that the VEGF binding with angiopoietin has a higher potential to promote angiogenesis than using only $\operatorname{VEGF}^{20,23}$. Although the neovascularization value was lower than the value of group 3, the isolated use of VEGF showed improvement in ejection fraction values, systolic and diastolic diameters of the left ventricle, as well as group 4, in which it was used stromal fraction of adipose derived mesenchymal cells.

Cell therapy with stromal fraction of stem cells (group 4) showed results similar to those found in VEGF + Ang1 group comparing neovascularization (no significant difference), averaging $41.4 \%$ neovascularization and $49.4 \%$ respectively. In relation to decreased akinetic area, a decrease of $34 \%$ for cell therapy and $61 \%$ for group VEGF + Ang1, affirming the angiogenic potential and the potential decline in akinetic area of mesenchymal cells ${ }^{22,25}$, and promotes improvement in rates ejection fraction, diastolic and systolic diameter of the left ventricle.

\section{Conclusions}

The VEGF and VEGFR with Angpt1 therapies promoted the morphofunctional restoration of the myocardium after an acute event of myocardial ischemia, which consequently causes irreversible morphological changes. For recovery to take place there must be an increase in neovascularization of the ischemic; this recovery is characterized by the reduction of the akinetic area enhancing the functional recovery of the heart as well.

\section{References}

1. Goichberg P, Chang J, Liao R, Leri A. Cardiac stem cells: biology and clinical applications. Antioxid Redox Signal. 2014 Nov 10;21(14):2002-17. doi: 10.1089/ ars.2014.5875.

2. Kai D, Wang QL, Wang HJ, Prabhakaran MP, Zhang Y, Tan YZ, Ramakrishna S. Stem cell-loaded nanofibrous patch promotes the regeneration of infarcted myocardium with functional improvement in rat model. Acta Biomater. 2014;10:2727-38. PMID: 24576580.

3. Garbern JC, Lee RT. Cardiac stem cell therapyand the promise of heart regeneration. Cell Stem Cell. 2013 Jun 6;12(6):689-98. doi: 10.1016/j. stem.2013.05.008.

4. Okamoto OK, Campos AH. Perspective in cell therapy: stem cells. Einstein. 2004;2(4):3558. PMID: 5349705.

5. Bydlowski SP, Debes AA, Maselli LM, Janz FL. Biological characteristics of mesenchymal 
stem cells. Rev Bras Hematol Hemoter. 2009;31:25-35.

6. Oliveira MD, Campos AH. Adult stem cells therapy for the heart. Einstein. 2009;7(2):229-36. doi: 10.1001/ jamacardio.2016.2225.

7. Danoviz ME, Nakamuta JS, Marques FLN, Santos L, Alvarenga E, dos Santos AA, Antonio EL, Schettert IT, Tucci PJ, Krieger JE. Rat adipose tissue-derived stem cells transplantation attenuates cardiac dysfunction post infarction and biopolymers enhance cell retention. Plos One. 2010;5(8):1-9. doi: 10.1371/journal. pone.0012077.

8. Mozid AM, Arnous S, Sammut EC, Mathur A. Stem cell therapy for heart diseases. Br Med Bull. 2011;98:143-59. PMID: 3785654.

9. Penn MS, Dong F, Klein S, Mayorga ME. Stem cells for myocardial regeneration. Clin Pharmacol Ther. 2011;90:499-501. doi: 10.1161/CIRCRESAHA.111.243071.

10.Eschenhagen T, Zimmermann WH. Engineering myocardial tissue. Circ Res. 2005;97:122-31. PMID: 16582915.

11.Valina C, Pinkernell K, Song $Y$, Bai X, Sadat S, Campeau RJ, Le Jemtel TH, Alt E. Intracoronary administration of autologous adipose tissue-derived stem cells improves left ventricular function, perfusion, and remodeling after acute myocardial infarction. Eur Heart J. 2007;28:2667-77. PMID: 17933755.

12.Mariano M. Miniature swine (minipig) in biomedical experimental research: the Minippig br1. Acta Cir Bras. 2003;18(5):387-91. doi: 10.1590/S010286502005000800008.

13.Littell RC. Statistical Analysis System. 2009. doi: 10.1002/9780470057339.

14.Souza CF, Napoli P, Han SW, Lima VC, Carvalho ACC. Mesenchymal stem cells: are they appropriate for cardiac regeneration? Rev Bras Cardiol Invasiva. 2010;18(3):344-53. doi: 10.1590/S2179-83972010000300019.

15.Zuk PA. The adipose-derived stem cell: looking back and looking ahead. Mol Biol Cell. 2010;21:1783-7. doi: 10.1091/mbc. E09-07-0589.

16.Chen J, Li Y, Wang L, Zhang Z, Lu D, Lu $M$. Therapeutic benefit of intravenous administration of bone marrow stromal cells after cerebral ischemia in rats. Stroke. 2001;32(4):1005-11. PMID: 11283404.

17.Bartunek J, Vanderheyden $M$, Vanderkerckhove B, Mansour S, De Bruyne $B$, De Bondt P. Intracoronary injection of CD-133 positive enriched bone marrow progenitor cells promotes cardiac recovery after recent myocardial infarction: feasibility and safety. Circulation. 2005;112(9):178-83. PMID: 16159812.

18.Vulliet PR, Greeley M, Halloran SM, Macdonald KA, Kittleson MD. Intra-coronary arterial injection of mesenchimal stromal cells and microinfarction in dogs. Lancet. 2004;363(9411):783-4. doi: 10.1016/S01406736(04)15695-X.

19.Angeli FS, Oliveira EM. Cell therapy in the treatment of acute myocardial infarction. Rev Bras Cardiol Invasiva. 2007;15(2):145-50. doi: 10.1590/S2179-83972010000400018.

20.Chae JK, Kim I, Lim ST, Chung MJ, Kim WH, Kim HG. Coadministration of angiopoietin-1 and vascular endothelial growth factor enhances collateral vascularization. Arterioscler Thromb Vasc Biol. 2000;20:2573-8. doi: 11.1321/s1198-034-0057-s.

21.Babiak A, Schumm AM, Wangler C, Loukas $\mathrm{M}, \mathrm{Wu}$ J, Dombrowski S, Matuschek C, Kotzerke J, Dehio C, Waltenberger J. Coordinated activation of VEGFR-1 and VEGFR-2 is a potent arteriogenic stimulus leading to enhancement of regional perfusion. Cardiovasc Res. 2004;61(4):78995. doi: 10.1186/s12872-015-0027-z.

22.Strauer BE, Brehm M, Zeus T, Bartsch T, Schannwell C, Antke CO. Regeneration of human infracted heart muscle by intracoronary autologous bone marrow cell transplantation in chronic coronary artery disease: the IACT Study. J Am Coll Cardiol. 2005;46(9):1651-8. doi: 10.1016/J. JACC.2005.01.069..

23. Rosengart TK, Lee LY, Port JL, Hahn RT, Devereux RB, Finnin E. Video assisted epicardial delivery of angiogenic gene therapy to the human myocardium utilizing an adenovirus vector encoding for VEGF12. Circulation. 2012;100:758-70. doi: 10.1172/ C118583.

24.Gordon O, Gilon D, He Z, May D, Lazarus A, Oppenheim A, Keshet E. Vascular endothelial growth factor-induced neovascularization 
rescues cardiac function but not averse remodeling at advanced ischemic heart disease. Arterioscler Thromb Vasc Biol. 2012 Jul;32(7):1642-51. doi: 10.1161/ ATVBAHA.112.248674.
25.Lopes JP, Fiarresga A, Cunha OS, Feliciano J, Ferreira RC. Mesenchymal stem cell therapy in heart disease. Rev Port Cardiol. 2013;32:43-7. doi: 10.1016/j. repce.2012.11.005.

\section{Correspondence:}

André Lacerda de Abreu Oliveira Laboratório de Sanidade Animal, Centro de Ciências e Tecnologias Agropecuárias

Unidade de Experimentação Animal, UENF Darcy Ribeiro

Avenida Alberto Lamego, 2000

28013-602 Campos dos Goytacazes-RJ Brasil

Tel.: (55 22)2748-6084

lacerdavet@uol.com.br

Received: Dec 26, 2017

Review: Feb 22, 2018

Accepted: Mar 23, 2018
Conflict of interest: none

Financial source: none

\begin{abstract}
${ }^{1}$ Research performed at Laboratory of Animal Health and Laboratory of Cell and Tissue Biology, Animal Experimentation Unit, Universidade Estadual do Norte Fluminense Darcy Ribeiro (UENF), and Molecular and Cellular Cardiology Laboratory, IC/FUC Institute of Cardiology of Rio Grande do Sul, University Foundation of Cardiology, Porto Alegre-RS, Brazil.
\end{abstract}

